\title{
EVALUATION OF FINANCIAL MECHANISMS FOR ENERGY- EFFICIENT INTERVENTION PROJECTS IN LOW-INCOME COMMUNITIES: A CASE STUDY FOR KUYASA, CAPE TOWN
}

\author{
Thembinkosi Maphosa', Abdullah Bayat' ${ }^{2}$, Harold Annegarn ${ }^{3}$
}

\begin{abstract}
:
The Kyoto Protocol Article 12 Clean Development Mechanism (CDM) under the United Nations Framework Conversion on Climate Change (UN FCCC), focuses on delivering sustainable development through compliance with quantified emission limitation and reduction commitments. This study explores the financial mechanisms within the Clean Development Mechanism framework to finance energy-efficient interventions projects in Kuyasa low-income community, Khayelitsha in Cape Town. A purposive sample of three hundred and seventy (370) Kuyasa residents and fifteen (15) experts on renewable energy were interviewed using self-completed questionnaires and in-depth interview schedules, respectively. Data were analyzed using descriptive statistics and content analysis. The majority of the respondents confirmed that the project lacked post-implementation sustainable financial mechanisms to fund the maintenance and upgrades of the 2309 houses retrofitted with solar water heaters, compact fluorescent lights, and insulated ceilings. Attempts to impose a R30 contribution per household, which was not initially agreed at the conception of the project, was rejected by the Kuyasa project beneficiaries. Equally, an attempt to charge an 'availability' charge was unsuccessful, because beneficiaries could not afford to pay. Similarly pre-project revenue expected revenue streams through selling Certified Emission Reductions (CERs) and they were negatively affected by delays and decline in CERs credit values. Lastly, the proposal to monetize the monthly government grant of $50 \mathrm{kWh}$ per month to low-income households, was still under consideration while this study was conducted. Overall, the failure to develop a sustainable finance mechanism resulted in the Kuyasa renewable energy project recording a negative net present value. The study recommends that project implementers should apply holistic approaches that engender a buy-in by all stakeholders. There is a need for forward planning with respect to post-project funding imperatives and revenue streams that ensure the financial sustainability of projects.
\end{abstract}

Keywords: Clean Development Mechanism, Financial mechanisms, Kuyasa, Sustainability, Solar water heaters, Work With People

\footnotetext{
${ }^{1}$ University of the Western Cape; tmaphosa@uwc.ac.za

2University of the Western Cape; abbayat@uwc.ac.za

${ }^{3}$ North-West University; hannegarn@gmail.com
} 


\section{Introduction}

The South Africa White Paper on Energy Policy recognized that approximately 2.2 million low-income dwellings would be constructed over the coming years, but there was concern that insufficient attention was being paid to the thermal performance of these low-cost housing units (Energy Sector Management Assistance Program, ESMAP, 2011 ; 2012). Building houses in low-cost residential areas without attention to thermal performance, reduces initial costs slightly, exposes residents to a lifetime of low thermal comfort, high energy costs, and high levels of energyrelated air pollution (South Africa-Low income Energy Efficiency Housing Project, SA-LEEHP, 2015).

\section{Kuyasa Clean Development Mechanism Project}

The Kuyasa renewable energy efficiency project commenced in 2005 as a Clean Development Mechanism (CDM) project in partnership with the United Nations Framework Convention on Climate Change ( UN-FCCC). The purpose of the clean development mechanism as per Kyoto Protocol Article 12 for the United Nations Framework Conversion on Climate Change (UN FCCC) according to Africa et al (2012), was to assist Parties not included in Annex I towards achieving sustainable development. The ultimate objective of the Convention is to assist Parties included in Annex I towards compliance with their quantified emission limitation and reduction commitments under Article 3.

The objectives stated above underpinned the installation of CDM renewable energy technologies in 2309 Reconstruction and Development Programme (RDP) houses in Kuyasa, Khayelitsha from August 2008 to 2010 (Ashun and Kashani, 2011). The installed renewable energy technologies included solar water heaters (SWH), compact fluorescent lights (CFL) and insulated ceilings (Banks and Schaffler, 2006). The projected greenhouse gas savings from these three interventions are shown in Table 1 below.

Table 1: Anticipated greenhouse gas reductions (CO2e) from the Kuyasa project

\begin{tabular}{|l|l|l|}
\hline & Source & \multicolumn{1}{|c|}{$\begin{array}{c}\text { CO } \text { emissions } \\
\text { (tonnes/hh/year) }\end{array}$} \\
\hline Baseline & & 8.44 \\
\hline & Water heating & 1.288 \\
Intervention & Lighting & 0.228 \\
& Space heating & 1.330 \\
\hline Total for all 3 interventions & 5.60 \\
\hline Total avoided $\mathrm{CO}_{2}$ emissions per household & 2.85 \\
\hline
\end{tabular}

Adapted from Goldman, 2010

The project management expectations were that the project should be financially sustainable through the sale of Certified Emission Reduction (CER) credits to Annex 1 countries.

\section{Specific Clean Development Mechanism interventions in Kuyasa, Khayelitsha:}

The renewable energy project installed 110-litre solar water heaters (SWH), insulated ceilings and compact fluorescent light bulbs (CFL) in each of the selected dwellings. The aim was to alleviate energy poverty by providing the poor with access to renewable energy efficient technologies. A related objective was to address the 'suppressed demand' for energy services due to poverty and lack of infrastructure - both in terms of changing the 'demand patterns for energy' to enable the poor to 'meet these needs with less energy', and in turn to stimulate the local manufacturing demand for solar water heaters (Department of Environmental Affairs and Tourism, DEAT, 2005 and United Nations Framework Convention for Climate Change, UNFCCC, 2017). 
The Kuyasa renewable energy was the first Clean Development Mechanism project in Africa and was awarded the status of a Gold Standard Project. Over a 21-year crediting lifetime, the project was expected to generate at least 130,000 tonnes of CDM credits for sale (South Africa National Treasury, 2003). Secondly, the value of the Kuyasa Project was in terms of its contribution to sustainability goals focusing on climate change. These goals elevated the status of the project to the forefront of the City of Cape Town's climate change mitigation projects (Cartwright and Atkins, 2014). SouthSouthNorth (SSN) was the joint project implementer with the City of Cape Town. SSN is a nongovernmental organisation (NGO) with offices in South Africa, Bangladesh and Brazil. The timeline for the project from 1999- 2010 is shown in Table 2 below.

Table 2: Kuyasa project timeline

\begin{tabular}{|l|l|}
\hline Year & Activity \\
\hline $1999-2002$ & Kuyasa CDM project concept development \\
\hline 2003 & Pilot phase of 10 installations \\
\hline Late 2004 & CDM project documents submitted \\
\hline August 2005 & Kuyasa CDM project registered \\
\hline August 2006 & Agama selected to prepare business plan for implementation \\
\hline Late 2007 & SAEDF appointed implementer with revised business plan \\
\hline Early 2008 & 1800 installations completed \\
\hline Late 2009 & Remainder of 2309 installations completed \\
\hline April 2010 & Scheduled completion of 2309 \\
\hline
\end{tabular}

Adapted from Goldman, 2010

The project was developed and implemented in a way that allowed it to qualify for Certified Emission Reduction certificates in August 2005. As a Gold Standard project, the CDM project was registered under the Kyoto Protocol Article 12 Clean Development Mechanism (CDM) (Modi et al, 2006). The total cost of the project was originally estimated at R13.4 million - R6 000 per house. R12.5 million was required for initial capital expenditure and R0.9 million for maintenance over 10 years (Modi et al, 2006).

The central aim of this study is to evaluate the CDM financial mechanism used in the Kuyasa renewable energy project. The primary objectives are to a) evaluate the effectiveness of the financial mechanisms that were put in place in the development of the Kuyasa project and b) assess impacts of the implementation of renewable energy projects such as the Kuyasa project in Cape Town.

\section{Literature review}

The study is underpinned by the Real Options (RO) and Work With People (WWP) theories.

\section{Real Options (RO) theory}

The Real Options theory (RO theory) focuses on assessing the value of flexibility within projects under uncertain conditions (Cesena, 2012; Real Options in theory and Practice, 2008). The flexibility represents the capabilities of managers to adjust projects in response to uncertainties, and to enhance the project's worth (Ashun and Kashani, 2011). The RO theory approach applies the concept of financial options to the investment in physical assets, and takes into account both the net present value (NPV) and the irreversibility, uncertainty and managerial flexibility of physical investments (Cesena, 2012). 
In terms of the RO theory, an investment is a stochastic process which is potentially affected by several uncertainties which can be quantified. These intrinsic properties of an investment enables investors to evaluate project value more accurately and make investment decisions dynamically to minimise the investment risk (Cesena, 2012). If the NPV is positive the project is worthwhile and should be pursued. If it is negative the project should be turned down (Howells et al, 2010).

Decision-making under the traditional NPV criteria is normally based on static data and information, and cannot provide updated information for supporting dynamic decision-making for investments that need to consider uncertainties in the future Cesena, 2012). Thus the investment flexibility tends to be ignored. As a result, this method fails to provide an objective evaluation of the investment, and cannot solve the investment timing optimization problem (ESMAP, 2012). Thus, the theory of Real Options has emerged to solve the problems with traditional NPV criteria (Cesena, 2012).

\section{Work With People theory (WWP)}

The WWP theory advocates the need for systematic or open communication between participating agents as a precondition for participation in renewable energy projects. Participating agents involved in the Kuyasa project were the Kuyasa community members, Government through the Department of Energy (DoE), the former Department of Environmental Affairs and Tourism (DEAT), project owner (City of Cape Town), and project implementer (SouthSouthNorth). Eskom, the South African electricity power utility played a major role in the project.

The WWP theory argues that the social complexity of the private-public partnership is directly related to understanding the dynamics of the ethical-social component of the social partners. The WWP theory emphasizes incorporation of the behaviour of individuals and the context in which they work, and the need to avoid narrow focus on the technical aspects of projects (Lloyd, 2014). The WWP theory is underpinned by the belief that the value in improving human behaviour is achieved through the direct participation and involvement of the social partners. The model incorporates the behaviours, attitudes and values of people involved in the implementation of projects. Thus, the WWP theory offers a long-term sustainability approach and positive view of the reality, and allows actions to be taken with a perspective on the success, and the possibility of responding appropriately to the needs of the community (Cesena, 2012). The model is of great importance to the study in assessing the financial mechanism adopted by participating agents and community members. The WWP model highlights the importance of learning from one another through interaction and working together as proposed by the systems theory (Banks and Schaffler, 2006). More importantly, the WWP places emphasis on the need to avoid the traditional technicaleconomic vision of project management in low-income-earning communities and advocates the need to focus on individuals' behaviour and on the social context. These new elements make project management a complex process where all the different values, interests, appreciations, needs, expectations and commitments of each stakeholder play a role. This study adopted the Real Options and Work With the People theories to evaluate the net present value of the Kuyasa renewable energy project.

\section{Methodology}

The study adopted a case study design to evaluate the sustainability of financial mechanisms in the Kuyasa renewable energy project in Cape Town. A self-completed questionnaire was used to collect data from 370 Kuyasa residents. The study population comprised all the stakeholders and beneficiaries of the Kuyasa renewable energy project. In-depth interviews were conducted with 15 experts on renewable energy.

Purposive sampling was employed to select participants for this study. Dudovskiy (2018) and Lavrakas (2008) note that purposive sampling is a type of non-probability sampling where elements selected for sampling are regarded as experts. A pilot study was conducted to test the validity and reliability of the questionnaire. The respective items were addressed before the main field work. Participants were assured that the information was going to be used for the sole purpose of this study and that anonymity would be maintained.

Data analysis used content and discourse analysis. 


\section{Findings}

\section{Funding mechanisms for the Kuyasa project}

The study findings showed that the project received funding from national and regional governments. The former Department of Environmental Affairs and Tourism (DEAT) provided R24 million for the project fund, while the Western Cape Provincial Department of Housing and Local Government provided R4 million (US\$530 000) during the course of the project. The DEAT grant was to be recovered over time in the form of payments by residents and carbon credits (Goldman, 2010). In terms of Certified Emissions Reductions (CER) income, the project was expected to generate approximately R1 million (US\$130 000) per year through selling 6580 carbon credits per year, which would contribute to covering the South African Export Development Fund (SAEDF) guarantee, as well as ongoing maintenance and monitoring (Cartwright and Atkins, 2014).

It was reported that $30 \%$ of the funding went towards local job creation and skills development. SSN as a joint project implementer positioned the project as part of the National Government's Expanded Public Works Programme (EPWP) to create employment. The DEAT was responsible for directing EPWP funding which was earmarked towards a) reducing and alleviating unemployment and b) environmental projects which were to be achieved through inviting proposals from interested projects and organisations (Lockwood, 2013).

The study findings showed that unemployed members of the Kuyasa community were recruited and trained in carpentry, plumbing and electrical skills. The training was a mixture of in-house skills transfer, where an insourced technical expert would spend a week with the local team until they were competent enough to complete the installations. Outsourced accredited training was offered to enable skilled workers to acquire certificates in their specific skills (Goldman, 2010).

\section{Mechanisms to finance project costs and ongoing maintenance of the renewable energy technologies}

The study findings showed that there were four (4) planned financial contribution mechanisms to finance Kuyasa project costs. These funding mechanisms were:

1. A R30 monthly contribution by householders;

2. An 'availability' charge on the pre-paid electricity meters;

3. Revenue through selling Certified Emission Reductions (CERs); and

4. Monetising the basic energy grant.

The Work With People theory advocates for teamwork amongst the stakeholders involved in a project (Cesena, 2012). More importantly, is the need for the project owner, the project implementer and the community to work together on project implementation modalities. Thus the successful implementation of the financial mechanisms would depend on prior agreement between the partners. The findings reported below, point to a lack of adoption of the tenets of the WWP theory and Real Options theory that would have guaranteed a positive net present value (NPV) for the project.

The majority of the respondents cited the rationale and outcomes for each of the adopted financing mechanisms as follows:

a) $R 30$ monthly contribution

It was reported that the objective of the CDM project was to enhance the sustainability and livelihood opportunities for the low-income earning residents of Kuyasa. The project commenced with a 100 percent grant or capital injection for each RDP house (Wesselink, 2017). Initially residents were not expected to contribute to costs of installation and ongoing maintenance. The requirement for monthly contributions was mooted towards the end of the project. The demand for 'later' contributions was critical to ensure that the project become financially self-sustainable as there was no revenue stream and no 'afterward' collection mechanism (Wesselink, 2017).

A community survey in late May 2008 indicated that every household would be prepared to contribute at least R30 (US\$4) per month, with some offering up to R300 (US\$40). Wesselink, the SSN South Africa country manager, 
decided to apply R30 because "it was the lowest that anybody offered ... on R30 per month we can pretty much make Kuyasa work financially". Most of the project beneficiaries had agreed to the arrangement but the challenge was in the collection mechanism (SA-LEEHP, 2017). Ndamane, Kuyasa site manager, cautioned that "the collection of this R30, it can be a nightmare if I go house to house... I will be inviting robbery and all that." Alternatively, receiving the money paid at the Kuyasa CDM office was risky and also invited robbery. According to Wesselink, if the plan had materialized, the Kuyasa CDM project could have generated revenue amounting to R831 240 annually (R30 multiplied by 12 months multiplied by 2309 households), which would fully finance the budget shortfall within five years.

The projected income between December 2010 and December 2016 was R4 987 440, calculated as R831 240 multiplied by 5 years. Wesselink stated that the money could have been allocated towards promoting sustainability through maintenance and upgrades, as well as contributing towards value added tax (VAT) for the South African economy. He pointed out that the implementation of an efficient and effective revenue model could have guaranteed self-sustainability for the Kuyasa project.

SSN managers highlighted that a viable revenue model could have ensured continuous replication and added value to the renewable energy project for other communities in Khayelitsha, Wellington, and Kraaifontein. SSN managers further noted that the project needed a revenue model that ensured a buy-in from the residents through monthly contributions towards maintenance and upgrade of SWH, insulated ceilings and CFL.

\section{b) Availability charge on the pre-paid electricity meters}

The study showed that the project owners had initiated an 'availability charge' on the pre-paid electricity meters to be used in RDP houses. Prepaid electricity meters were installed by Eskom in low-income houses that were connected to the electricity grid during the past 15 years. In order to use electricity, the households were expected to purchase tokens from a retailer and enter the encoded 20-digit number using a keypad on the meter. Once the available credit is exhausted, the supply of electricity is cut off, until another token is purchased and entered.

A pilot was mooted with Eskom, where Kuyasa residents were encouraged to make their contributions by paying an additional R7 (US\$0.93) per week via the meter before they could access $1 \mathrm{~kW}$ of electricity. This contribution would then be redirected to the project (Goldman, 2010 and Wesselink, 2017). The solution did not materialise, because residents could not afford the weekly contribution. This was largely due to the fact that $70 \%$ of households in Khayelitsha survived on less than R1 600 (US\$213) per month (SouthSouthNorth, Africa, 2005).

\section{c) Monetise the basic energy grant}

This is an "even simpler [solution] which government can implement tomorrow". Some of the interviewees stated that project revenue would have been realized through monetising the basic energy grant of $50 \mathrm{kWh}$ per month provided by the government to all low-income households, including the 2309 in Kuyasa. The 'in-kind' grant was enough to provide basic lighting, basic water, heating, using a kettle, basic ironing and access to a TV and radio. The proposal was still under consideration while this study was conducted. Wesselink noted that he hoped "for a positive decision that would help unlock the financing needed for large-scale roll-out, and shift at least $50 \%$ of the risk in servicing this market segment to the State, where it more appropriately belongs".

d) Revenue through selling Certified Emission Reductions (CERs)

SSN management noted the possibilities of generating revenue through selling carbon credits and Certified Emission Reductions (CERs) to Annex 1 countries under the Kyoto Protocol. Verification of the Certified Emission Reduction (CER) had its own challenges. Verification of the Kuyasa CDM project covered the period August 2008 to December 2010 and was finalised in March 2017. SSN managers confirmed that the verification process was complicated and they had to pay R500 000 to the DOE, a European organisation. The carbon credits for that period were released and sold at 8 Euro per tonne. In total the CDM project for that period received R1 million. According to SSN management the money received was enough for basic maintenance but not to replace, for example, broken geysers, falling ceilings or burnt-out compact fluorescent lights. 
Verification for the period 2011 to 2015 was done by Credible Carbon, a South African renewable energy organisation which financed its operations from the carbon credits it generated. Locally the carbon credits were sold for between R70-R100 per tonne. Some of the carbon credits were sold to organisations such as Nedbank. Locally SSN received about R150 000. Combined international and national CERs revenues amounted to R1 150000 . According to Wesselink (SSN) the money received was channeled towards maintenance, repaying the debt (DEAT grant) the Kuyasa CDM accumulated for the period 2008 to 2010. Wesselink stated that the lack of constant revenue streams was jeopardising the sustainability of the Kuyasa (CDM) renewable energy project.

\section{Contribution towards economic growth}

Most of the experts interviewed were of the opinion that the South African economy made little profit from the tax payments from the Kuyasa CDM project. Wesselink highlighted that the project created more Chinese jobs compared to South African manufacturing jobs. The SSN management reported that they purchased the first 1500 geysers from a new local importer for a Chinese company called Genergy. The payments for the geysers were made within the project budget of R3 000 per geyser. The local importer had approval from the South African Bureau of Standards (SABS). Wesselink noted in an interview that although the geysers or solar water heaters (SWH) were approved, they were 'badly' insulated.

An additional one thousand (1 000) geysers were purchased from Hotmix (Pty) Ltd, a South African geyser manufacturing company. The Xstream Vacustream brand geysers sourced from Hotmix (Pty) Ltd were supplied at R3 800 per unit. The Xstream geysers had a lifetime guarantee against corrosion. The enhanced quality, improved safety and higher service cost levels increased costs slightly. The benefits from sourcing from the domestic manufacturing company, justified the increases on the total project budget and slightly longer payback period for the SAEDF guarantee (ESMAP, 2012).

Kuyasa Energy Company, a former early participant on the project was undertaking most of the maintenance on the renewable energy installations in Kuyasa community. The manager, Ndamane started off as a site manager of the Kuyasa (CDM) renewable energy project in October 2007. His responsibilities involved technical and non-technical aspects of the project. Upon project completion in 2010, experienced and confident, Ndamane registered the Kuyasa Energy Company. The company is located in Kuyasa, Khayelitsha within the renewable energy project area. Wesselink stated that some of the monies accumulated through the sale of Certified Emission Reductions (CERs) was channeled towards contracting Kuyasa Energy Company for maintenance. Maintenance was required for malfunctioning geysers, falling ceilings and other renewable energy installations for the RDP houses in Kuyasa.

\section{The environmental impact versus earned certified emission reductions}

The study findings showed that environmental challenges were addressed, as reflected by significant reductions in greenhouse gas emission. The project managed to reduce 2.85 tonnes of greenhouse gas emission per lowincome house per year. As a registered project under the Kyoto Protocol Clean Development Mechanism the 2.85 tonnes reduction of greenhouse gas emission was to be converted into carbon credits that could be sold and earned income for the project through certified emission reductions. Certified emission reductions income realised for the verified period between 2008 and 2010 was approximately R1.1 million against a capital injection of R33 million, thus indicating a negative net present value.

\section{Impact of carbon credits}

The study indicated that the carbon value had fallen and was approximately US $\$ 15$ per tonne versus the expected US\$25 per tonne in 2017. The European Union Observer (20 September 2017) highlighted that the price of the European carbon credits under the EU's Emissions Trading System (ETS), dropped from around €8 to slightly below $€ 6$ on 25 January 2017. It has fluctuated around $€ 6$ since then. This means that the project implementer would most likely get less income through the sale of carbon credits, thus putting the project maintenance and upgrades at substantial risk. 


\section{Contractual agreements between community members and key stakeholders}

The study findings showed a failure of the project implementer and owner to agree upfront contractual agreements with beneficiary community members. This failure proved costly to both partners during the project maintenance and upgrade phase. The income earned through the sale of certified emission reductions was barely enough to cover maintenance work. A severe rainstorm in Cape Town on 7 June 2017 left some of the solar water heaters needing maintenance. The damage resulted in some solar water heaters that had to be replaced and/or upgrades of hot water storage tanks (geysers) and solar collectors. An ongoing maintenance exercise could have been guaranteed through an agreed community member monthly contribution of R30/R40 per month.

\section{The importance of community member contributions}

The study findings support the Work With People theory which advocates for partners to actively participate through contributing financially and non-financially towards project costs. This would have channeled the contributions by beneficiary members towards project costs, thereby transferring the project ownership to them. In turn the monthly contributions would have generated a positive net present value as advocated by the Real Options Theory. Consequences of non-implementation of financial mechanisms

The consequences of the rejection by the beneficiary members of the R30 monthly financial contribution, had wider implications for the sustainability of the project. The study noted positive and negative economic impacts for the beneficiary members and wider community before and during the renewable energy interventions. Firstly, the community members highlighted a positive saving through the reduction in spending towards energy costs. According to Ndamane, a former Kuyasa project manager, a community member who previously spent about R500 (US\$67) per month on 50 litres of paraffin, was now spending less than R25 (US\$3.30) per month on about 2 litres of paraffin. Another resident reported a drop in electricity usage from R100 (US\$13.33) to R70 (US\$9.33) per month.

An SSN case study on the project in 2007 suggested an energy cost saving of R625.83 (US\$83.44) per household per year. Notwithstanding these cases, the absence of viable financial mechanisms will have negative consequences on the funding of maintenance costs and upgrades in the future, and ultimately reverse the expected outcomes of the renewable energy project.

\section{Conclusions}

The study findings indicate that the Kuyasa project contributed to a better quality of life for the beneficiaries of the renewable energy project initiative. It also created employment opportunities and stimulated the nascent growth of the renewable energy manufacturing sector. Notwithstanding the positive outcomes, the Kuyusa project had a negative net present value. The sustainability of the project was compromised by a lack of open communication and consultation regarding the financial mechanism between the key stakeholders.

Beneficiary members were not expected to contribute to costs of installation and ongoing maintenance. The project implementer should have anticipated the future financial mechanisms during the project conception phase as advocated by the WWP theory. The attempt to introduce 'later' contributions was rejected by the beneficiary members. Similarly the members were unable to pay the 'availability' charge on the pre-paid electricity meters. In turn, the project funding model over-estimated the revenue flows from selling certified emissions reductions (CERs), which was subject to uncontrollable external factors. The revenue stream was only sufficient for basic maintenance rather than replacing broken geysers, falling ceilings or burnt-out compact fluorescent lights. The proposal to monetise the basic energy grant had not yet been accepted by the government while this study was being conducted.

Overall, the financial mechanism for the Kuyasa (CDM) renewable energy had a negative net present value, which threatened the self-sustainability envisioned in renewable energy projects.

\section{Recommendations}

Project implementers should adopt holistic approaches when implementing private-public partnerships. The social complexity of projects should be taken into account through fostering mutual understanding among all the key stakeholders. Dual focus should be placed on the technical and social aspects in the implementation of projects 
which affect low-income communities. More importantly, contractual agreements should be agreed upon at the beginning of the project cycle as well as provision of timely updates over the project life cycle.

There is a need to align projects with relevant state regulations and laws, as well planning for unanticipated changes in commitments with international partners, institutions, bodies and governments.

\section{References}

Africa. L, Blore. M, Dwight. R, Reichhardt. C, Retief. D, and Mpando. T, (2012), “Domestic Energy Use of Low Income Households in Grahamstown East", South Africa.

Ashun. B, and Kashani. H, (2011), "A Real Options Approach to Evaluation Investment in Solar Ready Buildings"

Banks. D and Schaffler. J, (2006), "The Potential Contribution of Renewable Energy in South Africa: Update Report", Raps Consulting, South Africa.

Cartwright. A and Atkins. P, (18 June 2014), "Credible Carbon: Kuyasa Low-cost Urban energy upgrade project", South Africa

Cesena. E.A.M, (2012), "Real Options Theory Applied to Renewable Energy Generation Projects Planning", University of Manchester, School of Electrical And Electronic Engineering, London.

Department of Environmental Affairs and Tourism (DEAT)., (September 2005), "South Africa Country Report, Fourteenth Session of the United Nations Commission on Sustainable Development", South Africa.

Energy Sector Management Assistance Program (ESMAP), (2011), "Good Practices in City Energy Efficiency- Cape Town- Kuyasa Settlement",

Energy Sector Management Assistance Program (ESMAP), (2012), "Good Practices in City Energy Efficiency- Cape Town- Kuyasa Settlement"

Energy Sector Management Assistance Program (ESMAP), (2014), "Good Practices in City Energy Efficiency- Cape Town- Kuyasa Settlement"

EPG Working Paper: 1304, (2016), University of Exeter, United Kingdom.

Goldman. M, (2010), "Kuyasa CDM Project: Renewable energy efficient technology for the poor", South Africa.

Howells. M, Jonsson. S, Kack. E, Lloyd. P, Bennett. B, Leiman. T, and Conradie. B, (2010), “Calabashes for Kilowatthours: Rural Energy and Market Failure, Energy Policy", 38 (2010): 2729-2738.

Lloyd. P, (2014), "Challenges in household energisation and the poor", Journal of Energy in Southern Africa, Vol 25 No 2. May 2014, South Africa.

Lockwood. M, Kuzemko. C, Mitchell. C, and Hoggett. R, (2013), "Theorising governance and innovation in sustainable energy transitions",

Lu. Z, Liebman. A, and Dong. Z.Y, (2006), "Power Generation Investment Opportunities Evaluation: A Comparison between Net Present Value and Real Options Approach", in IEEE Power Engineering Society General Meeting.

McLeod. R, and Mitlin. D, (1993), The search for sustainable funding systems for community initiatives- Environment and Urbanisation, SAGE Social Science Collections, Volume 5Number 1.

Modi. V, McDade. S, Lallement. D, and Saghir.J, (2006), "Energy and the Millennium Development Goals", New York: Energy Sector Management Assistance Programme, United Nations Development Programme, UN Millennium Project, and World Bank.

Real options in theory and practise, (2008), accessed on website: http://www.essaytown.com/subjects/..realoptions-theory-financial-management/45194 (27/11/2017).

Rios-Carmenado. I.D, Ortuno. M, and Rivera. M, (2016), "Private-Public Partnership as a Tool to Promote Entrepreneurship for Sustainable Development: WWP Torrearte Experience.

South Africa-Low income Energy Efficiency Housing Project (SA-LEEHP), (2015), South Africa.

South Africa-Low income Energy Efficiency Housing Project (SA-LEEHP), (2017), South Africa. 
South Africa National Treasury, (2003), "Public Finance Management Act No 1 of 1999", South Africa.

SouthSouthNorth Africa., (2005), "Kuyasa Low Cost Housing Energy Upgrade Project, Khayelitsha, South Africa", SouthSouthNorth Africa. Available at: www.southsouthnorth.org [Accessed September 9, 2009].

United Nations Environment Programme (UNEP), (2015), A UNEP Study on "International Experiences on Sustainable Consumption' for China Council for International Cooperation on Environment and Development (CCICED)", China.

United Nations Framework Conversion on Climate Change (UNFCCC) - Certified Emission Reductions (CERs) report, (2017), available on website: http://www.cdm.unfccc.int/about/index.h

Wang. T, and de Neufville. T, (2005), "Real Options in Projects", in 9th Annual Real Options International Conference, Paris, France.

Wesselink. C, (2017). Country leader South Africa, SouthSouthNorth, Cape Town. South Africa, (Expert interview, June. 26, 2017). 